\title{
Manejo da cobertura do solo e de práticas conservacionistas nas perdas de solo e água em Sumé, PB'
}

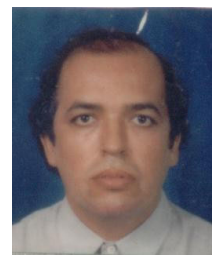

\author{
Abel W. Albuquerque ${ }^{2}$, Francisco Lombardi Neto ${ }^{3}$, Vajapeyam S. Srinivasan ${ }^{4} \&$ José R. Santos ${ }^{2}$ \\ 1 Parte da Tese de Doutorado do primeiro autor, apresentada à Escola Superior de Agricultura "Luiz de Queiroz", \\ Piracicaba, SP \\ 2 CECA/UFAL. Campus A.C. Simões, Cidade Universitária, Tabuleiro dos Martins, CEP 57072-970, Maceió, AL. \\ Fone: (82) 350-3148. E-mail: awa@fapeal.br (Foto) \\ 3 IAC. CP 28, CEP 13001-970, Campinas, SP. Telefax: (19) 3231-5422, Ramal 165. E-mail: flombard@barao.iac.br \\ ${ }^{4}$ DEC/UFPB. CEP 58109-970, Campina Grande, PB. Fone: (83) 310-1289. E-mail: vajapeya@dec.ufpb.br
}

Protocolo $091-26 / 7 / 2000$

\begin{abstract}
Resumo: Foram estudados os efeitos do manejo e da cobertura do solo sobre as perdas de solo e água provocadas por chuvas erosivas, num solo Bruno Não-Cálcico. Os dados correspondentes aos anos de 1983 a 1990 foram obtidos na Bacia Experimental de Sumé, PB, inserida dentro da Bacia Representativa de Sumé e operada pela Universidade Federal da Paraíba (UFPB), Campus II, Campina Grande. O experimento constituiu-se de uma parcela desmatada e mantida em alqueive contínuo, de duas desmatadas, uma com caatinga nativa, de duas parcelas com cobertura morta, uma com palma cultivada morro abaixo e de uma parcela com palma cultivada em nível. A parcela desmatada em alqueive contínuo contribuiu com perdas anuais de solo e água de 23,1 t ha-1 e $201 \mathrm{~mm}$, respectivamente. Nas parcelas desmatadas as perdas de solo e água foram de 35,7 e 58,5 t ha-1 e 224,2 e $241,0 \mathrm{~mm}$, respectivamente, enquanto a parcela com caatinga nativa e quando comparada com a parcela desmatada, teve uma redução na perda de solo em cerca de $99 \%$ e na perda de água em torno de $89 \%$; já nas parcelas com cobertura morta houve redução de aproximadamente $99 \%$ das perdas de solo e $74 \%$ das perdas de água em relação às parcelas desmatadas. A palma cultivada em nível reduziu as perdas de solo em $53,4 \%$, quando comparada àquela cultivada morro abaixo.
\end{abstract}

Palavras-chave: erosão, manejo do solo, semi-árido

\section{Effect of the soil cover management and conservation practices on soil and water losses of a Haplargid soil in Sumé, Paraíba State, Brazil}

\begin{abstract}
The effect of the soil cover management and conservation practice on soil and water losses caused by the erosivity of rainfall in Haplargid soil have been analyzed in this paper. The field data corresponding to the years 1983-1990 were collected at the Experimental Basin of Sumé, PB operated by the Federal University of Paraíba (UFPB). The experimental data resulting from one erosion plot cleared bare of vegetation and continuously ploughed in, two cleared bare runoff plots, one runoff plot with native semiarid vegetation, two mulched runoff plots, one plot with cactus planted down the slope and one plot with cactus planted along contour lines were used in the analysis. The bare ploughed plot contributed with annual soil and water losses of $23.1 \mathrm{t} \mathrm{ha}^{-1}$ and $201 \mathrm{~mm}$ respectively. In the cleared runoff plots, the soil losses were of 35.7 and $58.5 \mathrm{t} \mathrm{ha}^{-1}$ and the water losses of 224.2 and $241.0 \mathrm{~mm}$, respectively. The runoff plot with native semiarid vegetation when compared with the bare runoff plots, showed a reduction in the soil losses of about $99 \%$ and the water losses of around $89 \%$, while in mulched runoff plots there was a reduction of approximately $99 \%$ of soil losses and $74 \%$ of water losses when compared with the bare plots. The contour planted cactus plot reduced the soil losses by about $53.4 \%$ compared with the down the slope planted cactus plot.
\end{abstract}

Key words: erosion, soil management, semiarid region

\section{INTRODUÇÃO}

Na medida em que o manejo do solo, nas diversas atividades humanas, elimina a cobertura vegetal, sua superfície fica mais exposta à ação do impacto das gotas de chuva e da enxurrada.
Desta forma, tanto o impacto das gotas de chuva quanto à enxurrada contribuem para modificar as condições físicas da superfície do solo, alterando a rugosidade superficial, a porosidade e a taxa de infiltração de água. O efeito da cobertura do solo na redução da velocidade do escoamento superficial 
da água é explicado pela tortuosidade dos caminhos a serem percorridos pelo fluxo, imposta pelos resíduos, bem como pela barreira física proporcionada pelos resíduos vegetais, impedindo o livre escoamento da água, sendo que esta redução é tanto maior quanto maior for a quantidade de resíduos vegetais ou culturais na superfície (Carvalho et al., 1990; Levien et al., 1990; Reichert \& Cabeda, 1992; Anjos et al., 1994 e Steiner, 1994).

Em estudos realizados em várias regiões do Nordeste do Brasil, objetivando-se avaliar as perdas de solo em parcelas mantidas continuamente descobertas e cultivadas morro abaixo, indicaram-se perdas médias anuais de solo que variaram de 27 a 94 t ha $^{-1}$ (Margolis et al., 1985 e Silva et al., 1989).

A pressão demográfica no semi-árido do Nordeste do Brasil tem exigido uma demanda crescente de produtos agrícolas e florestais, condicionando um rápido incremento da produção agrícola, o qual tem sido feito às custas do desmatamento indiscriminado da caatinga, com conseqüente degradação do solo. O desmatamento indiscriminado para a formação de novas lavouras, aliadas à retirada de madeira para benfeitorias, lenha e carvão, e às queimadas sucessivas com manejo inadequado do solo tem contribuído, juntamente com as secas prolongadas, para comprometer o frágil equilíbrio do meio ambiente da região. Assim, a destruição da caatinga na região semi-árida do Nordeste brasileiro tem contribuído para acelerar a erosão do solo trazendo, como conseqüências, o seu empobrecimento e $\mathrm{o}$ assoreamento de mananciais (Albuquerque et al., 2001).

Utilizando chuva simulada para estudar o efeito do desmatamento da caatinga sobre as perdas de solo de um Neossolo Litólico, Ramos \& Marinho (1981) constataram que a parcela desmatada contribuiu com perdas de solo de 115,4 tha $\mathrm{t}^{-1}$. As parcelas com caatinga e extrato herbáceo proporcionaram perdas de 1,2 e 8,6 t ha-1 ${ }^{-1}$, respectivamente, com a redução das perdas de solo em 99,0 e $92,6 \%$, respectivamente. Os autores constataram, também, que o desmatamento reduziu a infiltração de água em $41,0 \%$.

Por sua vez, Margolis et al. (1985) avaliando o efeito de diferentes tipos de cobertura vegetal sobre as perdas por erosão, constataram que a palma forrageira cultivada num solo Litólico de Caruaru, PE, contribuiu com perdas de solo e de água, da ordem de 2,0 t ha ${ }^{-1}$ e $36,0 \mathrm{~mm}$, respectivamente.

A utilização do plantio em nível, em substituição ao plantio morro abaixo, tem demonstrado boa eficiência no controle das perdas por erosão, com redução das perdas de solo entre 40 e 50\% (Mondardo et al., 1978; Bertoni \& Lombardi Neto, 1985; Margolis et al., 1985; Silva et al., 1989 e Margolis et al., 1991).

O presente trabalho tem como objetivo avaliar os efeitos do manejo da cobertura do solo e de práticas conservacionistas sobre as perdas por erosão hídrica de um solo Bruno NãoCálcico, no município de Sumé, PB.

\section{MATERIAL E MÉTODOS}

Os dados utilizados no trabalho foram coletados na Estação Experimental de Sumé, PB, operada pela área de Recursos Hídricos do Campus II da Universidade Federal da Paraíba (UFPB), em Campina Grande. A estação está localizada na Fazenda Nova, no município de Sumé, PB, situada na altura do $\mathrm{km} 118$ da BR-412, entre as cidades de Sumé e Monteiro, na latitude de $7^{\circ} 40^{\prime}$ Sul e longitude $37^{\circ} 00^{\prime}$ Oeste, com altitude entre 500 e $700 \mathrm{~m}$.

De acordo com a classificação de Köeppen, o clima da região é do tipo climático BSh, (semi-árido), caracterizado por insuficiência e irregularidade das precipitações pluviais e ocorrência de temperaturas elevadas (Cadier et al., 1983). A precipitação pluvial média anual, observada no período de 1986 a 1990, foi de $695 \mathrm{~mm}$. A temperatura média anual histórica é de $24^{\circ} \mathrm{C}$ e a umidade relativa média anual de 57\% (Cadier et al., 1983).

O solo no local do experimento é um Bruno Não-Cálcico vértico, A fraco, textura argilosa fase caatinga hiperxerófila, (Luvissolo Hipocrômico Órtico vértico, A fraco, textura argilosa fase caatinga hiperxerófila). As análises textural e química encontram-se na Tabela 1. A vegetação predominante na área do experimento é a caatinga hiperxerófila densa.

O registro diário das chuvas ocorridas no período de 1983 a 1990 foi feito utilizando um pluviógrafo do tipo IH, localizado na estação meteorológica adjacente ao experimento. Para o cálculo da energia cinética das chuvas foram cortadas as chuvas individuais erosivas em segmentos de intensidade constante, através do método proposto por Wischmeier \& Smith (1978). Os valores obtidos foram posteriormente transferidos para o programa computacional desenvolvido por Cataneo et al. (1982), onde foram calculados os valores da energia cinética e do parâmetro da erosividade da chuva $\left(\mathrm{EI}_{30}\right)$ respectivamente. A equação utilizada para o cálculo da energia cinética e convertida para o Sistema Internacional de Unidades (Foster et al., 1981) foi àquela proposta por Wischmeier \& Smith (1978):

$$
\mathrm{Ec}=0,119+0,0873 \log _{10} \mathrm{I}
$$

em que: Ec: energia cinética da chuva, em $\mathrm{MJ} \mathrm{ha}^{-1} \mathrm{~mm}^{-1}$, e I: intensidade de chuva em cada segmento com intensidade constante, em $\mathrm{mm} \mathrm{h}^{-1}$, sendo que para intensidades de chuva iguais ou superiores a $76 \mathrm{~mm} \mathrm{~h}^{-1}$ a energia cinética passa a ter 0 valor máximo de $0,2832 \mathrm{MJ} \mathrm{ha}^{-1}$.

$\mathrm{O}$ experimento constituiu-se de oito parcelas experimentais de $100 \mathrm{~m}^{2}$, com 22,13 m de comprimento e 4,52 $\mathrm{m}$ de largura, onde foram instalados os seguintes tratamentos: PW: descoberto e em alqueive contínuo, P1Dm e P2Dm - desmatamento; PCa: caatinga nativa; $\mathrm{P} 1 \mathrm{Cm}$ e $\mathrm{P} 2 \mathrm{Cm}$ : cobertura morta; $\mathrm{PPm}$ : palma cultivada morro abaixo, e PPn: palma cultivada em nível. As declividades mensuradas nas parcelas foram as seguintes: PW: 4,0\%, P1Dm: 3,8\%, P2Dm: 7,0 \%, PCa: 9,5\%, P1Cm: 3,9, P2Cm: 7,2\%, PPm: 4,0\% e PPn:.4,0\%. As parcelas foram

Tabela 1. Características textural e química dos horizontes minerais de um solo Bruno Não-Cálcico

\begin{tabular}{|c|c|c|c|c|c|c|c|c|c|c|c|c|c|}
\hline \multirow{3}{*}{ Horizontes } & \multicolumn{4}{|c|}{ Composição Granulométrica } & \multirow{3}{*}{$\begin{array}{c}\mathrm{pH} \\
\left(\mathrm{H}_{2} \mathrm{O}\right)\end{array}$} & \multicolumn{7}{|c|}{ Características Químicas } & \multirow{3}{*}{$\begin{array}{l}\text { M.O. } \\
\mathrm{g} \mathrm{kg}^{-1}\end{array}$} \\
\hline & $\mathrm{AG}^{1}$ & $\mathrm{AF}^{1}$ & $\mathrm{~S}^{1}$ & $\mathrm{ARG}^{1}$ & & \multirow{2}{*}{$\begin{array}{c}\mathrm{P} \\
\mathrm{mg} \mathrm{kg^{-1 }}\end{array}$} & $\mathrm{K}$ & $\mathrm{Ca}$ & $\mathrm{Mg}$ & $\mathrm{Na}$ & $\mathrm{Al}$ & $\mathrm{H}$ & \\
\hline & \multicolumn{4}{|c|}{$\mathrm{g} \mathrm{kg}^{-1}$} & & & \multicolumn{6}{|c|}{$\mathrm{cmol}_{\mathrm{c}} \mathrm{kg}^{-1}$} & \\
\hline $\mathrm{A}(0-10 \mathrm{~cm})$ & 240 & 320 & 250 & 180 & 6,3 & 2,6 & 0,30 & 7,0 & 5,7 & 0,63 & 0,05 & 4,52 & 12,4 \\
\hline $2 \mathrm{Bt}(10-50 \mathrm{~cm})$ & 300 & 210 & 160 & 330 & 5,7 & 0,5 & 0,17 & 7,9 & 11,5 & 1,82 & 0,57 & 5,26 & 1,20 \\
\hline
\end{tabular}

$\mathrm{AG}=$ Areia grossa; $\mathrm{AF}=$ Areia fina; $\mathrm{S}=$ Silte; $\mathrm{ARG}=$ Argila 
delimitadas por chapas galvanizadas e cravadas $15 \mathrm{~cm}$ no solo e, na suas extremidades inferiores foram instalados sistemas coletores de enxurrada, constituídos de uma calha conectada por um cano de PVC a um primeiro tanque de fibrocimento, localizado imediatamente abaixo da parcela, que por sua vez estava conectado ao segundo tanque de fibrocimento, através de um divisor de enxurrada do tipo "Geib" pelo qual, a nona parte do extravasamento do primeiro tanque entrava no segundo. Após cada chuva, amostras de enxurrada eram retiradas dos tanques coletores das parcelas para a determinação das perdas de solo e o volume total de água deixando as parcelas eram calculados (Cadier et al., 1983).

Nas parcelas desmatadas, adotou-se o critério de remover a vegetação com enxada quando a mesma atingia a altura de $5 \mathrm{~cm}$ em média, enquanto que as parcelas com cobertura morta foram roçadas quando a vegetação nativa atingia a altura de $25 \mathrm{~cm}$, sem retirá-la de dentro das parcelas, objetivando a formação de uma cobertura morta. As parcelas com palma forrageira foram cultivadas com enxada morro abaixo e em nível respectivamente, sendo que ambas as parcelas eram limpas quando o mato atingia $5 \mathrm{~cm}$ de altura. Por sua vez, o manejo da parcela descoberta e em alqueive contínuo seguiu as recomendações de Wischmeier \& Smith (1978), ou seja, a parcela foi mantida sem cobertura vegetal através do preparo e cultivo do solo com enxada, no sentido do declive.

\section{RESULTADOS E DISCUSSÃO}

\section{Distribuição da erosividade da chuva e da precipitação pluviométrica}

O valor médio anual da erosividade da chuva e da precipitação pluvial foram de $4.928 \mathrm{MJ} \mathrm{mm} \mathrm{ha}^{-1} \mathrm{~h}^{-1}$ e $695 \mathrm{~mm}$, respectivamente (Tabela 2). Na Figura 1 pode ser observada para efeito de comparação, a distribuição dos valores anuais da erosividade da chuva e da precipitação pluvial de Sumé,PB. A análise estatística tanto dos valores anuais da precipitação pluvial quanto da erosividade da chuva em Sumé,PB, indicou uma alta dispersão (Tabela 2). Essa dispersão indicada pelos parâmetros estatísticos, reflete a irregularidade da precipitação pluvial anual, que é uma característica da região semi-árida (Catalince \& Margolis, 1994; Albuquerque, 1997; Albuquerque et al., 2001).

Os maiores valores médios mensais da erosividade da chuva ocorreram nos meses de fevereiro a abril (Figura 2), cujos valores

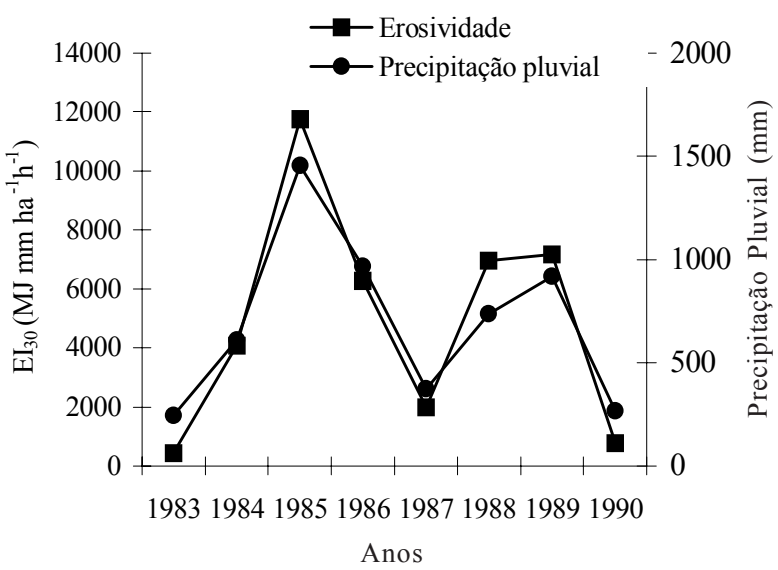

Figura 1. Distribuição dos valores anuais da erosividade da chuva e da precipitação pluvial

representam 53\% da precipitação pluvial e 79\% da erosividade em Sumé,PB. Na Figura 3 estão apresentados a distribuição dos valores médios anuais do índice de erosividade da chuva $\mathrm{EI}_{30}$ e as perdas de solo das parcelas desmatadas (P1Dm e P2Dm). Pode-se observar que a curva dos valores das perdas de solo e da erosividade das chuvas são semelhantes, ou seja, a medida em que aumenta a erosividade da chuva, aumenta também a perda de solo. A linha de regressão entre as perdas de solo das parcelas desmatadas (P1Dm e P2Dm) e o índice de erosividade $\mathrm{EI}_{30}$ pode ser vista na Figura 4. Os valores dos coeficientes de determinação $\left(\mathrm{R}^{2}\right)$ foram de 0,88 e 0,89 , indicando que 88 e $89 \%$ dos valores médios anuais de perdas de solo das parcelas

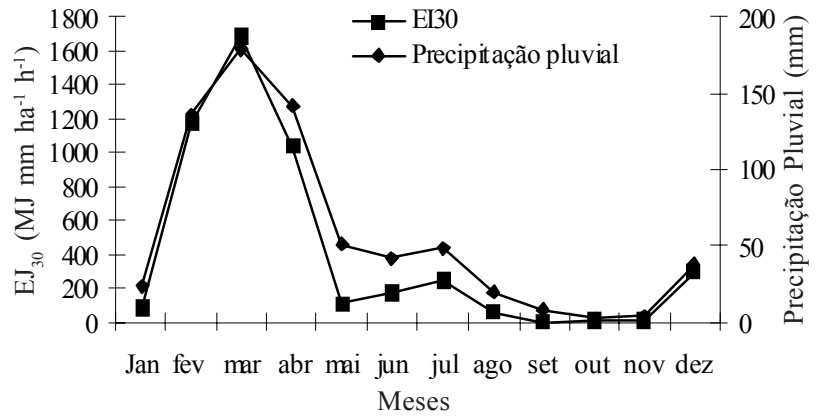

Figura 2. Distribuição temporal dos valores médios mensais da erosividade das chuvas e da precipitação pluvial em Sumé, PB

Tabela 2. Valores anuais e médios anuais da erosividade $\left(\mathrm{EI}_{30}\right)$, precipitação pluvial e das perdas de solo das parcelas experimentais, em Sumé, PB

\begin{tabular}{|c|c|c|c|c|c|c|c|c|c|c|}
\hline \multirow{3}{*}{ Ano } & \multicolumn{8}{|c|}{ Perda de Solo } & \multirow{3}{*}{$\begin{array}{c}\text { Chuva } \\
\mathrm{mm}\end{array}$} & \multirow{3}{*}{$\begin{array}{c}\mathrm{EI}_{30} \\
\mathrm{MJ} \mathrm{mm} \mathrm{ha}^{-1} \mathrm{~h}^{-1}\end{array}$} \\
\hline & $\mathrm{PW}^{1}$ & $\mathrm{PCa}^{1}$ & $\mathrm{P} \mathrm{Dm}{ }^{1}$ & $\mathrm{P}^{2} \mathrm{Dm}^{1}$ & $\mathrm{P} 1 \mathrm{Cm}^{1}$ & $\mathrm{P} 2 \mathrm{Cm}^{1}$ & $\mathrm{PPm}^{1}$ & $\mathrm{PPn}^{1}$ & & \\
\hline & \multicolumn{8}{|c|}{$\mathrm{t} \mathrm{ha}^{-1}$} & & \\
\hline 1984 & - & 0,0 & 32,6 & 83,2 & 0,3 & 0,8 & 6,0 & 2,4 & 608 & 4073 \\
\hline 1985 & - & 0,2 & 102,2 & 186,0 & 0,6 & 0,4 & 10,4 & 6,0 & 1.453 & 11.764 \\
\hline 1986 & 17,3 & 0,6 & 19,8 & 25,6 & 1,6 & 1,0 & 13,7 & 8,5 & 965 & 6.274 \\
\hline 1989 & 34,5 & 0,0 & 51,1 & 83,0 & 0,0 & 0,0 & - & - & 917 & 7.171 \\
\hline 1990 & 5,5 & 0,0 & 9,3 & 5,1 & 0,0 & 0,0 & - & - & 267 & 775 \\
\hline Média & 23,1 & 0,1 & 35,7 & 58,5 & 0,3 & 0,3 & 11,6 & 5,4 & 695 & 4.928 \\
\hline Desvio padrão & 18,1 & 0,23 & 33,6 & 61,1 & 0,6 & 0,4 & 10,6 & 4,6 & 413 & 3.864 \\
\hline C.V. $(\%)$ & 78,5 & 191,6 & 94,0 & 104,0 & 180,5 & 150,2 & 93,3 & 86,4 & 59 & 78 \\
\hline
\end{tabular}

PW - Parcela descoberta; PCNa - Parcela com caatinga nativa; P1Dm e P2Dm - Parcelas desmatadas; P1Cm P2Cm - Parcelas com cobertura morta; PPm - Palma cultivada morro abaix e PPn - Palma cultivada em nível 
desmatadas podem ser explicados pelos valores anuais do índice de erosividade, portanto, a concentração de $79 \%$ do índice de erosividade médio anual nos meses de fevereiro, março e abril, é um indicador de que se deve tomar medidas preventivas neste período do ano para proteger o solo da erosão hídrica, visto que, as maiores perdas de solo ocorreram durante estes meses.
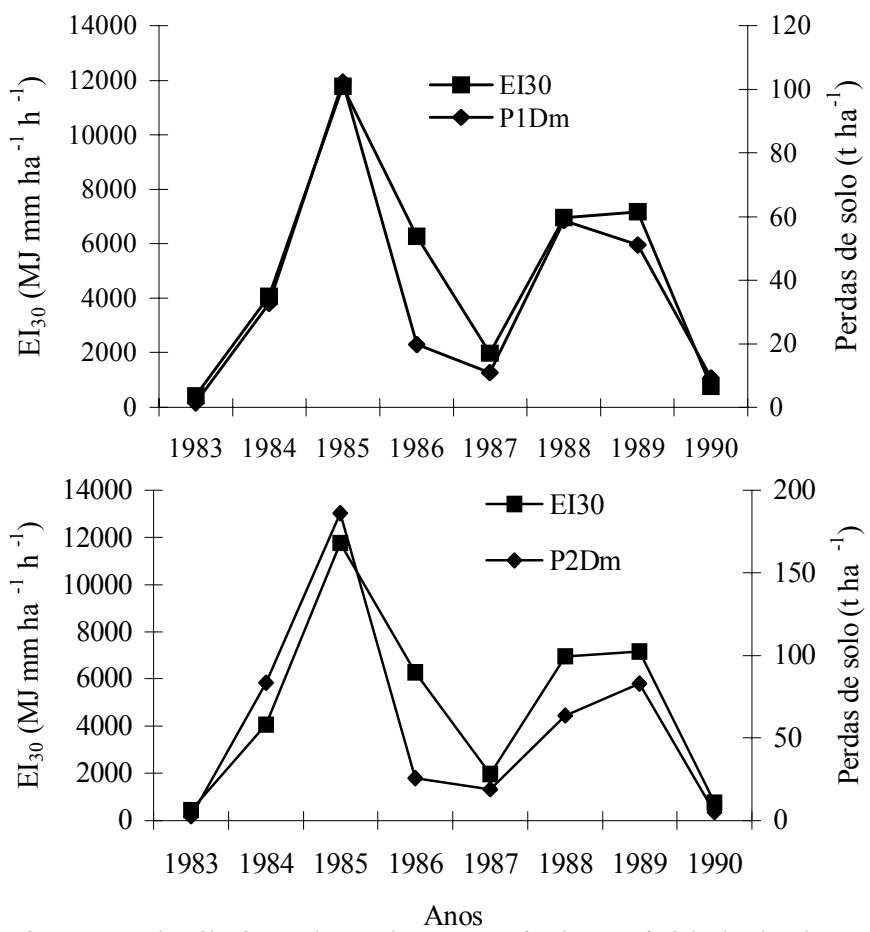

Figura 3. Distribuição dos valores anuais da erosividade da chuva e das perdas de solo das parcelas desmatadas (P1Dm e P2Dm)
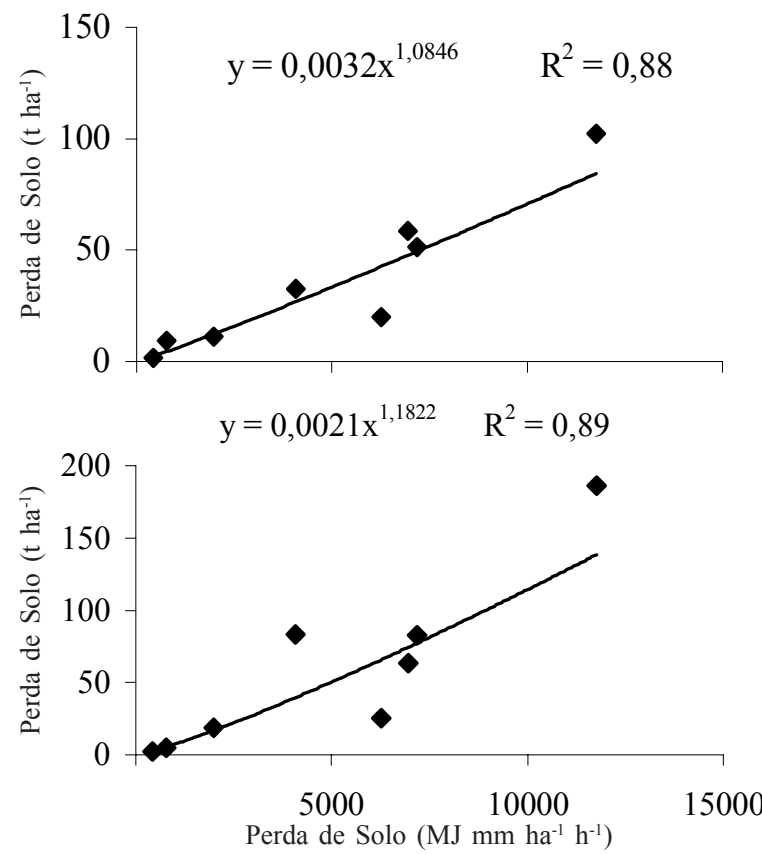

Figura 4. Relação entre os valores anuais do índice de erosividade $\mathrm{EI}_{30}$ e as perdas de solo das parcelas desmatada (P1Dm e P2Dm)

\section{Perdas de solo em parcelas experimentais}

Comparando-se o valor médio anual de perda de solo da parcela descoberta em alqueive contínuo (PW) e com o valor médio da parcela com caatinga nativa $(\mathrm{PCa})$, no período de
1983 a 1990, constata-se que o primeiro foi 231 vezes maior do que o segundo. Essa diferença está associada a remoção da cobertura vegetal da superfície do solo na parcela descoberta. A remoção da cobertura vegetal possibilitou à ação do impacto das gotas de chuva e do escoamento superficial sobre o solo descoberto, ocasionando a desagregação e transporte das partículas do solo como relatado por Ramos \& Marinho (1981); Reichert \& Cabeda (1992) e Albuquerque et al., (2001). Assim, constatou-se que as parcelas com caatinga nativa contribuíram para reduzir as perdas de solo em torno de $99 \%$, quando comparada com aquela descoberta.

Os valores médios anuais das perdas de solo, correspondente ao período de 1986 a 1990 obtido para as parcelas desmatadas (P1Dm e P2Dm) e Caatinga Nativa (PCa) foram de 35,7, 58,5 e 0,1 tha- $^{-1}$ respectivamente (Tabela 2). Comparando-se os valores médios anuais de perdas de solo da parcela com caatinga nativa com aquelas desmatadas, constata-se uma redução em torno de $99 \%$. Considerando-se que o manejo das parcelas desmatadas incluía apenas a remoção da vegetação com enxada, quando a mesma atingia $5 \mathrm{~cm}$ de altura, infere-se a partir dos dados obtidos, que a adoção de práticas agrícolas que impliquem numa mobilização mais intensiva do solo, poderá contribuir para aumentar em muito, os riscos de perda de solo por erosão hídrica.

Apesar da caatinga não ter a mesma pujança de uma floresta de mata atlântica, os resultados obtidos indicam um eficiente controle da erosão por parte da caatinga. Este fato está provavelmente associado à extraordinária capacidade de rebrota da caatinga por ocasião das primeiras chuvas, formando um dossel semelhante a uma floresta baixa, capaz de atenuar os efeitos do impacto das gotas de chuva sobre o solo. Por outro lado, durante a estação seca a caatinga hiperxerófila, por ser decídua, contribui para a formação de uma camada de folhas sobre a superfície do solo, atenuando o impacto das gotas de chuva e diminuindo o escoamento superficial sobre o solo como relatado por Mendes (1986), Reis (1988) e Albuquerque et al. (2001).

Assim, os valores médios anuais de perdas de solo das parcelas desmatadas e com caatinga nativa, evidenciam a importância da caatinga como agente controlador dos processos erosivos, mormente em solos rasos com horizonte B textural, tal como no solo estudado, podendo o seu desmatamento indiscriminado comprometer o solo e os mananciais da região.

As perdas médias de solo das parcelas com cobertura morta (P2Cm) e desmatada (P2Dm), foram de 0,3 e 58,5 t ha ${ }^{-1}$ respectivamente (Tabela 2), sendo que a parcela com cobertura morta reduziu as perdas de solo em $99 \%$, quando comparada com àquela desmatada. Fato que pode ser explicado quando se considera que a utilização da cobertura morta contribuiu para proteger a superfície do solo tanto do impacto das gotas de chuva, quanto do poder de desagregação e transporte da enxurrada, corroborando com os resultados obtidos por Carvalho et al. (1990); Levien et al. (1990) e Albert \& Neibling (1994).

Analisando-se os valores de perda de solo na cultura da palma (Tabela 2), constatou-se que pelo valor médio do período de estudo (1983 a 1988), o plantio dessa cultura em nível, apresenta nível de perda de solo bem inferior $\left(5,4 \mathrm{tha}^{-1}\right)$ àquele obtido com o cultivo da mesma, morro abaixo $\left(11,6 \mathrm{tha}^{-1}\right)$. Desta 
Tabela 3. Valores anuais e médios anuais da erosividade $\left(\mathrm{EI}_{30}\right)$, precipitação pluvial e das perdas de água das parcelas experimentais, em Sumé, PB

\begin{tabular}{|c|c|c|c|c|c|c|c|c|c|c|}
\hline \multirow{3}{*}{ Ano } & \multicolumn{8}{|c|}{ Perda de Água } & \multirow{3}{*}{$\begin{array}{l}\text { Chuva } \\
\mathrm{mm}\end{array}$} & \multirow{3}{*}{$\begin{array}{c}\mathrm{EI}_{30} \\
\mathrm{MJ} \mathrm{mm} \mathrm{ha}^{-1} \mathrm{~h}^{-1}\end{array}$} \\
\hline & $\mathrm{PW}^{1}$ & $\mathrm{PCa}^{1}$ & $\mathrm{P} \mathrm{Dm}^{1}$ & $\mathrm{P}^{2} \mathrm{Dm}^{1}$ & $\mathrm{P} 1 \mathrm{Cm}^{1}$ & $\mathrm{P} 2 \mathrm{Cm}^{1}$ & $\mathrm{PPm}^{1}$ & $\mathrm{PPn}^{1}$ & & \\
\hline & \multicolumn{8}{|c|}{$\mathrm{mm}$} & & \\
\hline 1984 & - & 5,0 & 199,4 & 221,0 & 43,1 & 75,4 & 90,5 & 39,0 & 608 & 4073 \\
\hline 1985 & - & 136,0 & 543,0 & 630,0 & 326,9 & 254,5 & 547,6 & 496,0 & 1.453 & 11.764 \\
\hline 1986 & 251,5 & 39,0 & 235,0 & 304,4 & 115,6 & 106,9 & 299,3 & 243,0 & 965 & 6.274 \\
\hline 1989 & 331,0 & 0,0 & 280,0 & 316,4 & 0,0 & 9,1 & - & - & 917 & 7.171 \\
\hline 1990 & 43,0 & 0,0 & 50,7 & 57,0 & 0,0 & 0,0 & - & - & 267 & 775 \\
\hline Média & 201,0 & 22,5 & 224,2 & 241,0 & 61,9 & 56,5 & 230,0 & 183,5 & 695 & 4.928 \\
\hline Desvio padrão & 140,2 & 47,8 & 171,0 & 196,2 & 114,3 & 89,7 & 201,0 & 188,2 & 413 & 3.864 \\
\hline C.V. (\%) & 69,8 & 212,4 & 76,3 & 81,4 & 184,4 & 158,7 & 87,3 & 102,6 & 59 & 78 \\
\hline
\end{tabular}

PW - Parcela descoberta; PCNa - Parcela com caatinga nativa; P1Dm e P2Dm - Parcelas desmatadas; P1Cm e P2Cm - Parcelas com cobertura morta; PPm - Palma cultivada morro abaixo e PPn - Palma cultivada em nível

forma, o cultivo em nível contribuiu para reduzir em torno de $53,4 \%$, as perdas de solo, quando comparado com o cultivo morro abaixo, corroborando com os resultados obtidos por Margolis et al. (1985); Bertoni \& Lombardi Neto (1985); Silva et al. (1989) e Margolis et al. (1991).

Uma comparação dos valores médios da erosão das parcelas com palma (morro abaixo 11,6 t ha ${ }^{-1}$ ) e palma em nível $\left(5,4 \mathrm{tha}^{-1}\right)$ com o valor médio anual obtido da parcela desmatada $\left(35,7 \mathrm{t} \mathrm{ha}^{-1}\right)$ no período de 1983 a 1988 , constata-se que as parcelas com palma proporcionaram redução das perdas de solo da ordem de 67,5 e $85 \%$ para plantio morro abaixo e plantio em nível, respectivamente, evidenciando o efeito protetor da cobertura vegetal e de práticas conservacionistas sobre as perdas de solo.

\section{Perdas de água em parcelas experimentais}

As perdas de água (Tabela 3) seguiram a mesma tendência das perdas de solo, porém, com reduções entre as parcelas menores do que aquelas observadas para as perdas de solo. As menores reduções das perdas de água ocorreram, provavelmente pelo fato do solo, independente do sistema de manejo, apresentar limitada capacidade de infiltração, a partir da qual a taxa de enxurrada tende a igualar-se em diferentes sistemas de manejo do solo, como relatado por Bertol (1994); Schick et al. (2000) e Albuquerque et al. (2001).

A parcela descoberta e em alqueive contínuo (PW) perdeu em torno de 9,0 vezes mais água que a parcela com caatinga nativa (PCa) pelo valor médio do período de estudo (Tabela 3 ). Assim, a perda de água da parcela descoberta em relação à precipitação média anual $(695 \mathrm{~mm})$ foi de $29 \%$, enquanto a perda de água da parcela com caatinga nativa foi de 3,2\%. Os dados evidenciam que as áreas onde a vegetação nativa foi preservada, a mesma contribuiu para aumentar de forma significativa, a infiltração da água no solo. Da precipitação média anual de 695 $\mathrm{mm}$, infiltrou-se $672 \mathrm{~mm}$, na parcela com a caatinga. Esses dados ressaltam o importante papel que a cobertura vegetal pode desempenhar no controle das perdas de água por escoamento superficial, principalmente quando se considera a irregularidade e a baixa precipitação pluvial da região semi-árida do Nordeste do Brasil.
As perdas de água das parcelas desmatadas (P1Dm e P2Dm) em relação a parcela com caatinga nativa ( $\mathrm{PCa}$ ) seguiram a mesma tendência da parcela descoberta (PW), mas, com maiores perdas, ou seja, perderam 10 vezes mais água em relação a parcela com caatinga nativa. Em termos da precipitação média anual, estas perdas foram de 32,2 e $34,7 \%$, respectivamente, para as duas parcelas citadas.

Comparando-se os valores obtidos das parcelas com cobertura morta (P1Cm e P2Cm) e parcela desmatada (P1Dm e $\mathrm{P} 2 \mathrm{Dm})$ pode-se constatar que as parcelas desmatadas $(224,2 \mathrm{e}$ $241,0 \mathrm{~mm}$ ) perderam em média 3,8 vezes mais água que as parcelas com cobertura morta $(65,0$ e $56,5 \mathrm{~mm})$. As perdas de água das parcelas com cobertura morta em relação à precipitação média anual, foram de 9,3 e 8,1\%, respectivamente. Através desses resultados (Tabela 3), constatou-se que as parcelas com cobertura morta tiveram um aumento significativo da infiltração de água no solo, em torno de $180 \mathrm{~mm}$.

Os valores médios anuais de perda de água das parcelas com palma morro abaixo e palma em nível, correspondentes ao período de 1983 a 1988, foram de 230,0 e $183,5 \mathrm{~mm}$, respectivamente (Tabela 3). As perdas de água das parcelas com palma cultivada morro abaixo e palma cultivada em nível (Tabela 3) em relação à precipitação pluviométrica média anual do mesmo período $(729,0 \mathrm{~mm}$ ) foram de 31,5 e $25,1 \%$, respectivamente. A comparação dos valores médios anuais da perda de água entre a parcela com o plantio em nível e plantio morro a baixo (Tabela 3 ), indica que o cultivo em nível contribuiu para reduzir em $20,0 \%$ as perdas de água em relação ao cultivo morro abaixo.

\section{CONCLUSÕES}

1. Na média dos tratamentos, a parcela com caatinga nativa foi eficaz na redução das perdas de solo, reduzindo-as em torno de $99 \%$ em relação à parcela descoberta e às parcelas desmatadas, destacando o papel fundamental da caatinga nativa no controle de erosão do solo. As perdas de água seguiram a mesma tendência, entretanto, essas reduções foram menores do que as perdas de solo.

2. As parcelas com cobertura morta, reduziram as perdas de solo e água em cerca de 99 e $74 \%$ respectivamente, em relação às parcelas desmatadas. 
3. Tanto as parcelas com caatinga nativa quanto as parcelas com cobertura morta, proporcionaram um aumento significativo da infiltração de água no solo, contribuindo para reduzir a erosão hídrica.

4. O cultivo em nível em relação àquele em desnível reduziu as perdas de solo e água em 53,4 e $20 \%$ respectivamente, portanto, por sua eficiência e simplicidade representa um importante instrumento no controle da erosão hídrica.

\section{AGRADECIMENTOS}

Os dados utilizados neste trabalho foram cedidos pela área de Recursos Hídricos da Universidade Federal da Paraíba (CCT/ UFPB), Campus II, Campina Grande-PB. A Superintendência para Desenvolvimento do Nordeste (SUDENE) e ORSTOM, a agência da pesquisa e cooperação internacional da França foram responsáveis para a implantação inicial da Bacia Experimental de Sumé e as primeiras coletas de dados. Os autores agradecem a grande contribuição dos técnicos destas instituições na realização deste trabalho.

\section{LITERATURA CITADA}

Albert, E.E.; Neibling, W.H. Influence of crop residues on water erosion. In: Unger, P.W. (Ed.). Managing agricultural residues. Flórida: Lewis Publi, 1994. cap.3, p.19-36.

Albuquerque, A.W. Determinação de parâmetros para a equação universal de perdas de solo nas condições de Sumé, PB. Piracicaba: Escola Superior de Agricultura "Luiz de Queiroz", Universidade de São Paulo, 1997. 133p. Tese Doutorado

Albuquerque, A.W.; Lombardi Neto, F.; Srinivasan, V.S. Efeito do desmatamento da caatinga sobre as perdas de solo e água de um Luvissolo em Sumé (PB). Revista Brasileira de Ciência do Solo, Viçosa, v.25, n.1, p.121-128, 2001.

Anjos, J.T.; Ubert, A.A.A.; Vizzoto, V.J.; Leite, G.B.; Krieger, M. Propriedades físicas em solos sob diferentes sistemas de uso e manejo. Revista Brasileira de Ciência do Solo, Campinas, v.18, p.139-145, 1994.

Bertol, I. Erosão hídrica em Cambissolo Húmico Distrófico sob a diferentes sistemas de preparo e cultivo do solo e rotação de cultura. Revista Brasileira de Ciência do Solo, Campinas, v.18,p.267-271, 1994.

Bertoni, J.; Lombardi Neto, F. Conservação do solo. Piracicaba: Livroceres, 1985.368p.

Cadier, E.; Freitas, B.J. de.; Leprun, J.C. Bacia Experimental de Sumé: Instalação e primeiros resultados. Recife: SUDENE, 1983. 87p. Série Hidrologia, 16

Carvalho, F.L.C.; Cogo, N.P.; Levien, R. Eficácia relativa de doses e formas de manejo do resíduo cultural de trigo na redução da erosão hídrica do solo. Revista Brasileira de Ciência do Solo, Campinas, v.14, p.227-234, 1990.

Catalince, J.R.B.; Margolis, E. Características das chuvas e correlação de índices de erosividade com as perdas de solo do Agreste de Pernambuco. Revista Brasileira de Ciência do Solo, Campinas, v.17, p.275-281, 1994.
Cataneo, A.; Castro Filho, C.; Acquarole, R.M. Programa para cálculo de índices de erosividade de chuvas. Revistas Brasileira de Ciências do Solo, Campinas, v.6, p.236-239, 1982.

Foster, G.R.; McCool, D.K.; Renard, K.G; Moldenhauer, W.C. Conservation of the Universal Soil Loss Equation the SI metric units. Journal of Soil and Water Conservation, Baltimore, v.36, p.355-359, 1981.

Levien, R.; Cogo, N.P.; Rockenbach, C.A. Erosão na cultura do milho em diferentes sistemas de cultivo anterior e métodos de preparo do solo. Revista Brasileira de Ciência do Solo, Campinas, v.14, p.73-80, 1990.

Margolis, E.; Galindo, I.C. de L.; Mello Netto, A.V. de. Comportamento de sistemas de cultivo da mandioca em relação à produção e às perdas por erosão. Revista Brasileira de Ciência do Solo, Campinas, v.15, p.357-362, 1991.

Margolis, E.; Silva, A.B. da.; Jacques, F. de O. Determinação dos fatores da equação universal de perda de solo para as condições de Caruaru-PE. Revista Brasileira de Ciência do Solo, Campinas, v.9, p.165-169, 1985.

Mendes, B.V. Desertificação do semi-árido. In: Seminário sobre Desertificação no Nordeste, Recife, 1986. Trabalhos apresentados. Brasília: Ministério do Desenvolvimento Urbano e do Meio Ambiente e Secretaria Especial do Meio Ambiente (SEMA), 1986. p.111-115.

Mondardo, A.; Henkain, J.C.; Faroas. G.S.; Vieira, M.J.; Rufino, R.L. Perdas por erosão em culturas anuais, em sistemas de preparo convencional e plantio direto, usando simulador de chuva. In: Encontro Nacional de Pesquisa sobre Conservação do Solo, 2, Passo Fundo, 1978. Anais... Passo Fundo: Sociedade Brasileira de Ciência do Solo, 1978. p.249-251.

Ramos, A.D.; Marinho, H.E. Estudo da erodibilidade de um solo litólico sem cobertura vegetal e sob duas condições de pastagens nativa de caatinga. Sobral: EMBRAPA, 1981. 16p. Boletim de Pesquisa, 2

Reichert, J.M.; Cabeda, M.S.V. Salpico de partículas e selamento superficial em solos do Rio Grande do Sul. Revista Brasileira de Ciência do Solo, Campinas, v.16, p.389-396, 1992.

Reis, J.G. Desertificação no Nordeste. Recife: SUDENE, 1988. $40 \mathrm{p}$.

Schick, J.; Bertol, I.; Batistela, O.; Balbinot Jr., A.A. Erosão hídrica em Cambissolo Húmico Alumínico submetido a diferentes sistemas de preparo e cultivo do solo: 1 . Perdas de solo e água. Revista Brasileira de Ciência do Solo, Campinas, v.24, p.427-436, 2000.

Silva, I.de F. da; Campos Filho, O.R; Andrade, A.P. de; Coêlho, E.A.C; Diniz, E.J. Influência do cultivo isolado e do consórcio sobre as perdas de solo e água numa terra roxa estruturada. Revista Brasileira de Ciência do Solo, Campinas, v.13, p.111-115, 1989.

Steiner, J.L. Crop residue effects on water conservation. In: Unger, P.W. (ed.) Managing agricultural residues. Flórida: Lewis Publications. 1994. cap.4, p.42-70.

Wischmeier, W.H.; Smith, D.D. Predicting rainfall erosion losses: A guide to conservation planning. Washington: USDA, 1978. 58p. USDA. Agricultural Handbook, 53 